\title{
DETECTING UNIVERSAL STRUCTURE AND EFFECTS OF TYPEFACES
}

\author{
Uroš Nedeljković, Dragoljub Novaković, Ivan Pinćjer
}

Original scientific paper This study investigates the effects of universal and specific characteristics of typefaces with combined method - through comparison of the results of digital analysis and subjects' responses to binary images stimuli. Results point to the dependency of the response in relation to the isolated characteristic of the universal structure. In other words, with the combined method in this study we disclose that certain attributes are assigned to typefaces in accordance with their matching or mismatching to the universal structure. The findings open the question of the functionality of existing classifications, and the need of redefining the old, or establishing the new classification systems of typefaces.

Keywords: SSIM; typeface; typeface personality; universal structure

Otkrivanje univerzalne strukture i djelovanja pisama

Izvorni znanstveni članak Ova studija istražuje učinke univerzalnih i specifičnih karakteristika pisama kombiniranom metodom - usporedbom rezultata digitalne analize i odgovora ispitanika na binarne slike podražaje. Rezultati ukazuju na zavisnost odgovora ispitanika u odnosu na izdvojeno svojstvo univerzalne strukture. Drugim riječima, kombiniranim postupkom, korištenim u ovom istraživanju, možemo otkriti da li su određena svojstva dodijeljena pismima sukladna s njihovim podudaranjem ili nesukladna s univerzalnom strukturom. Rezultati ovog istraživanja otvaraju pitanje funkcionalnosti postojećih klasifikacija i potrebu redefiniranja starih, ili uspostavljanja novih sustava klasificiranja pisama.

Ključne riječi: osobnost oblika pisma; pismo; SSIM; univerzalna struktura

\section{Introduction}

Only in printed or electronic media does the language become materially present, but with a new communicative value that is reflected through the visual component, or through the typeface. This observation is supported by research on the connotative value of typeface, or typography rhetoric. Findings of numerous researches indicate the responsibility on the part of the graphic designer to bring the texts or messages to life through the use of certain typefaces with a specific rhetoric potential.

Seeing that typefaces are the most common design element in visual materials, their role as an important visual tool is recognized by the researchers. Research of rhetoric potential of typefaces has confirmed the assumptions of practitioners that typefaces can have: a certain personality and mood $[1 \div 5]$ semantic associations $[6,7]$ and congeniality with the product [8,9], and therefore certain control over impressions and connotations $[7,10 \div 15]$.

A large number of researchers have endeavoured to assign certain attributes to typefaces. Mackiewicz and Moeller [3] have done research on the kind of personalities different typefaces have according to the subjects' assessment. They determined that subjects identify different personalities of typefaces based on their previous experience with those typefaces. Furthermore, subjects' comments imply that their perception of typeface personality is an intuitive act, meaning that the subjects had no principle to guide their differentiation of typeface personalities.

Studies of Eva Brumberger have been focused on examining if the personality of typeface and text is consistently perceived [1]. According to her assumptions, typography rhetoric is directly correlated with the typeface personality. After identifying personality for different typefaces, Brumberger tries in her studies $[1,16]$ to determine the relationship between the typeface personality and the appropriateness of the typeface for different kinds of textual content, or, respectively, the influence of appropriateness and the awareness of appropriateness of typeface.

General conclusion on the basis of literature review is that anyone who uses a typeface, whether it is to graphically design with it or just to type and set the text, needs to consider the impressions made by the typeface, in order to achieve the appropriate tone for the graphic material in question. However, if we want to know what are the specific attributes of typefaces which initiate different impressions we will arrive at a research problem that was not often dealt with by the researches up to now. Davis and Smith [9] have endeavoured to discover the way in which different form of attributes, or "mechanical characteristics", as they are uncommonly called, influence the feeling tone, or, in other words, the suitability of certain form attributes to specific content cases. Based on their findings, the authors came to the conclusion that the formal attributes having the biggest influence on the subjects' impression are the extreme size, character width and character brightness. Castle and Child [4] found that there is a connection between specific moods and specific variables of typefaces. However, the means of manipulation with the typographic stimuli in the mentioned studies, as well as the divided focus of the researches on multiple goals, reveal a certain confounding of variables which makes it hard to isolate with any certainty the specific, or universal characteristics that contribute to connection with the given attributes.

\section{Subject of research and research question}

Researchers like Brumberger and Mackiewicz base their empirical testimony on human perception of typefaces. However, in Eva Brumberger's study [1] subjects subjectively evaluated typefaces according to the list of 20 attributes with the goal of defining specific 
personalities for every typeface-stimuli, or consolidating factors for typeface groups. Different kinds of typefaces were chosen as the stimuli, from cursives and antiquas to sans-serif and decorative display typefaces. Using Principal components analysis, the author isolated three main factors, naming each factor according to the attributes with the best average value grade that is specific to the selected typefaces in the group. In that way, the first group called "elegant", according to the factor loadings, was populated by various calligraphic forms (see [17]), cursives, glyphics and graphics (VII-IX class according to British standardization BS 2961:1967 [18]); the second group called "direct" was populated by various antiquas and sans-serif typefaces (I-VI class according to BS 2961:1967 [18]); and the third group called "friendly" was populated by decorative and display typefaces.

Following this findings, we could assume that all typefaces from the first and the second basic class of the Vox-Atypi (see [17]) i.e. first six groups of the British Standardization BS 2961:1967 [18] are not perceived significantly different, and that all of them have a single, formal direct tone regardless of the fact that they have many different formal attributes (proportion, weight, $\mathrm{x}$ height, serif shape, etc.) (see [19]). The logic of this observation is attested by the division of the given classification to five more subclasses, with additional four sans-serif groups in the scope of the third class of the socalled modern forms. This finding might be considered acceptable by a layperson, since by choosing any typeface from this group with the intention of communicating "directly" they would not embarrass themselves. However, in line with the historical context and development of typefaces from the Renaissance up until the present day, and discussions of the new traditionalists and modernists, contemporary graphic communications designer and type-scholar cannot simply accept this finding uncritically. Many of these typefaces, even though primarily intended for text arrangement, according to the writings of many typography theorists possess: personality connotations [20], rhetoric potential [21], associations and expression [22, pp. 76-78], to which even the author attests in literature review. On the other hand, if we qualitatively analyse the Brumberger's finding, specifically the factor "direct", a significant piece of information is discovered. All of the mentioned typefaces possess a common type of skeleton, whose existence is advocated by Frutiger [23, pp. 200-203]. The common skeleton, which dates from as far away as humanistic typefaces, is discernable in the isolated factor as the seemingly only universal characteristic, i.e. latent principal component (Fig. 1). For Brumberger, given the plan of further research, analysis of the results in this direction was not considered a research goal.

According to Henderson et al. [10], typeface design can be differentiated by universal characteristics and characteristics specific to some typeface. As such, universal design characteristics are holistic descriptions that rely on perception and they can be used to describe a broad spectrum of diverse stimuli. A holistic description implies that a system should be observed as a whole instead of as an aggregate of parts. Typeface specific characteristics are graphic descriptions and they include characteristics such as: short/high, serif/sans-serif, compressed/expanded. These characteristics are not subjective and they provide an opportunity to further explain the difference in the responses specific to typeface design. However, all of the studies so far have not isolated the effect of the universal characteristics of typefaces, nor precisely defined what this term exactly means. The reason for this could be that the researchers used very structurally different typefaces for the stimuli. With the exception of Davis and Smith [9], who endeavoured, among other things, to find an answer to the question of which of the form attributes influence the impression by selectively choosing stimuli, the discovery of the sources of the influence was not the goal of other studies. The effect of specific characteristics on the perception of the typeface should be searched for only after the effects of universal characteristics have been empirically established, i.e. the deviation from the universal.

Based on the perceived and isolated research problem, a research question has been formed.

RQ: Which of the formal attributes, based on the evaluation of typeface personality and the processing and analysis of data, can we single out as influential, respectively, universal?

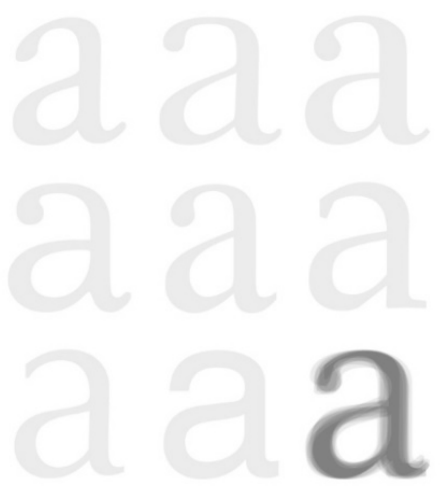

Figure 1 Model of the common skeleton according to Adrian Frutiger

\section{Method}

The answer to the research question was sought by performing the experiment in two ways: using the evaluation scale test and by using digital image analysis.

\subsection{Experiment with subjects}

The method of collecting data for this research was to modify the attribute scaling known as semantic differential. Subjects were given rating scales with unpaired attributes on a Likert scale from 1 to 7. They were given a task of evaluating personalities for eight typefaces with 20 different attributes on a scale with 7 value options, where an attribute like "cheap", for example, can have values of "very cheap" (7-6), "somewhat cheap" (5-3) and "not cheap at all" (2-1). Instructions about procedure were presented verbally, while the descriptions of the meaning of each attribute were presented in a written form.

Subjects in the experiment consisted of 40 students at the Faculty of Technical Sciences, University of Novi Sad, Serbia. There was an equal number of males and 
females amongst the subjects, between 20 and 30 years of age, with an average age of 21,47 .

Stimuli. Subjects were given the task of subjectively evaluating personalities for eight typefaces that were classified in the VI class "lineale" according to BS 2961:1967, in other words, sans-serif typefaces. Sansserif typefaces are, according to BS 2961:1967 and VoxAtypi, classified into sub-classes: grotesk, neo-grotesk, geometric and humanist. Therefore, two representatives of each group were chosen for the stimuli (Tab. 1). Since the typefaces differ in their formal attributes according to height and width of the character, stroke width, and some of them more or less according to skeleton too, it is expected that subjects should attribute different personalities according to obviously different formal attributes.

Table 1 List of typefaces (stimuli) used in the experiment, sorted in the order of classes and sub-classes in classifications by BS 2961:1967 and Vox-Atypi

\begin{tabular}{|l|l|l|c|}
\hline \multirow{4}{*}{$\begin{array}{l}\text { Lineale } \\
\text { (sans- } \\
\text { serif) }\end{array}$} & \multirow{2}{*}{$\begin{array}{l}\text { Grotesque } \\
\text { grotesque }\end{array}$} & Franklin Gothic Std No.2 & FRA \\
\cline { 2 - 4 } & \multirow{2}{*}{ Geometric } & Founders Grotesk-Medium & FGR \\
\cline { 2 - 4 } & & Helvetica LT Std & HEL \\
\cline { 2 - 4 } & Futura Std-Medium & DIN \\
\cline { 2 - 4 } & \multirow{2}{*}{ Humanist } & Grid Sans & FUT \\
\cline { 3 - 4 } & & Frutiger LT Std 55 Roman & FRU \\
\hline
\end{tabular}

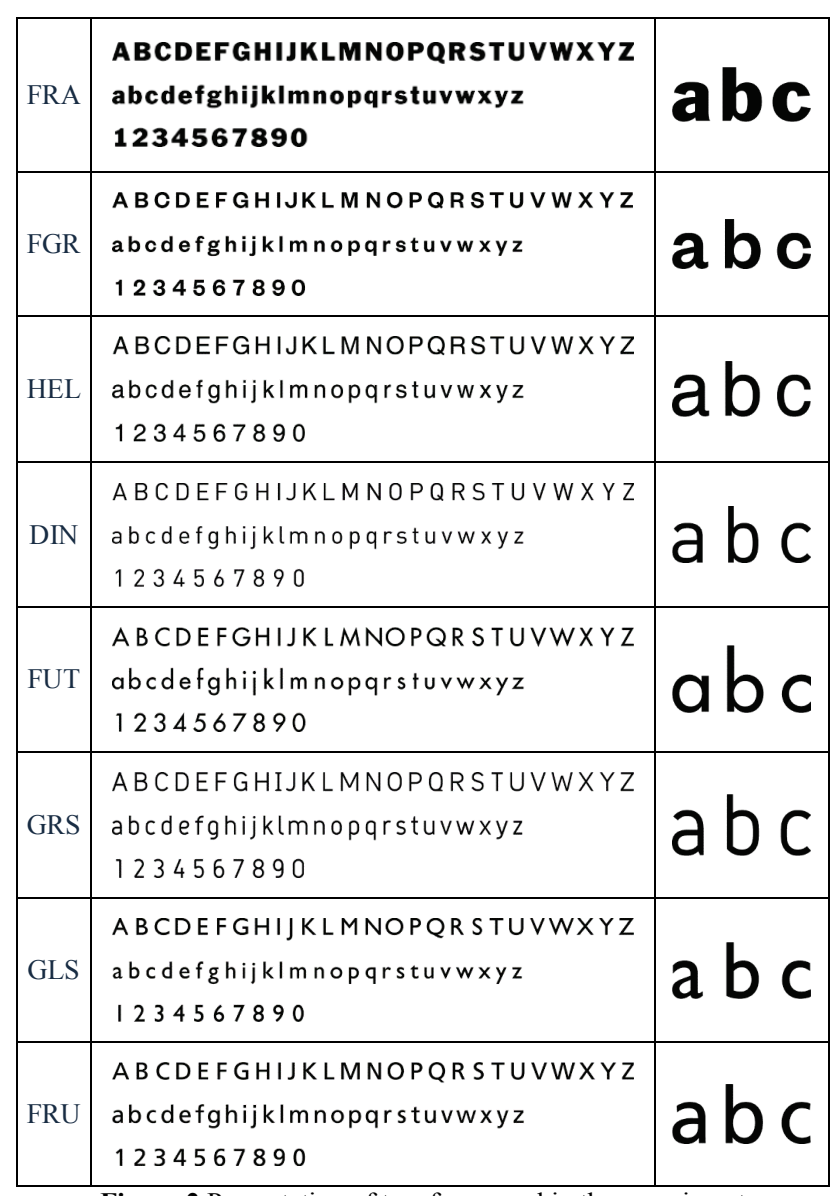

Figure 2 Presentation of typefaces used in the experiment

Instrument. Single-page printed leaves with test instruments for eight typefaces were binded in a booklet. Every printed page contained: complete group of alphanumeric characters (capital, small letters and numbers); a paragraph of placeholder text "Lorem ipsum"; and seven-point Likert scales for 20 following attributes: cheap, cold, reliable, dignified, elegant, feminine, formal, friendly, attractive, loud, masculine, contemporary, pretentious, professional, relaxed, scholar, serious, technical, direct and warm. All typefaces and paragraphs were presented in the same size; $14 \mathrm{pt}$ for the alphanumeric characters and $12 \mathrm{pt}$ for the paragraph, by means of which a visual contrast was achieved between every typeface sample and attribute scales which were presented on the same page. The page order is randomly determined in order to avoid the effect of hierarchy.

\subsubsection{Results of the evaluation scale test}

Results obtained by the research are statistically processed with an adequate selection of statistical methods, in order to secure an optimal model of perceiving the influence, dependence and differences between the analysed data obtained in the research.

Variance analysis. Data obtained by variance analysis (ANOVA) are used to determine if there is any statistically important difference between the typefaces for all of the attributes examined. ANOVA is used for the evaluation of differences for one discrete variable with more than two modalities, on a single continuous variable. In our case, typefaces were taken as discontinuous (discrete) variables. Degree of agreement with attributes was taken as a continuous variable.

Table 2 Mean values for typefaces according to the personality attributes examined

\begin{tabular}{|l|c|c|c|c|c|c|c|c|}
\hline & FRU & DIN & GLS & GRS & HEL & FRA & FUT & FRG \\
\hline Cheap & 2,95 & 2,92 & 3,15 & 3,10 & 3,55 & 4,02 & 3,05 & 3,57 \\
\hline Cold & 3,85 & 3,80 & 3,90 & 3,32 & 4,07 & 4,47 & 3,35 & 3,95 \\
\hline Reliable & 5,05 & 4,45 & 4,65 & 4,10 & 4,65 & 3,87 & 4,30 & 4,12 \\
\hline Dignified & 4,02 & 4,35 & 4,30 & 4,00 & 4,10 & 3,45 & 4,20 & 3,80 \\
\hline Elegant & 2,70 & 4,10 & 3,37 & 4,02 & 3,20 & 2,02 & 3,75 & 2,77 \\
\hline Feminine & 2,32 & 3,60 & 2,72 & 3,60 & 2,52 & 1,45 & 3,25 & 2,35 \\
\hline Formal & 4,80 & 4,17 & 4,25 & 3,60 & 4,47 & 3,02 & 3,82 & 3,85 \\
\hline Friendly & 3,87 & 3,57 & 3,77 & 4,07 & 3,65 & 2,97 & 4,17 & 3,75 \\
\hline Attractive & 3,30 & 3,92 & 3,80 & 3,92 & 3,90 & 2,75 & 4,22 & 3,62 \\
\hline Loud & 3,47 & 3,32 & 4,42 & 4,52 & 5,27 & 6,42 & 4,30 & 5,32 \\
\hline Masculine & 3,67 & 3,65 & 4,22 & 3,60 & 4,72 & 5,42 & 4,05 & 4,80 \\
\hline Contemporary & 4,47 & 4,35 & 4,77 & 4,55 & 4,60 & 4,10 & 4,70 & 4,40 \\
\hline Pretentious & 2,65 & 3,37 & 3,92 & 3,72 & 4,20 & 4,60 & 3,95 & 4,12 \\
\hline Professional & 4,35 & 4,10 & 4,20 & 3,82 & 4,27 & 3,22 & 3,87 & 4,10 \\
\hline Relaxed & 3,92 & 3,07 & 3,42 & 3,75 & 3,37 & 2,57 & 4,22 & 3,12 \\
\hline Scholar & 4,07 & 3,92 & 3,62 & 3,27 & 4,00 & 2,47 & 3,67 & 3,57 \\
\hline Serious & 4,77 & 4,20 & 4,22 & 3,82 & 4,82 & 3,95 & 3,92 & 4,32 \\
\hline Technical & 4,42 & 4,17 & 4,25 & 3,87 & 4,10 & 3,45 & 3,62 & 3,80 \\
\hline Direct & 5,30 & 4,55 & 4,97 & 4,52 & 5,27 & 5,65 & 4,62 & 4,85 \\
\hline Warm & 2,85 & 3,10 & 3,42 & 3,57 & 3,05 & 2,57 & 3,67 & 3,45 \\
\hline
\end{tabular}

Variance analysis shows that there is a statistically significant difference on the level of $p<0,05$ on all of the attributes except three: dignified, contemporary and technical. Typefaces were estimated very similarly for these three attributes, i.e. attributes are obviously common to all examined (sans serif) typefaces. Therefore these three variables will be excluded from discussion. As ANOVA does not supply information on the groups between which there are differences, Post Hoc Test was done in order to obtain this information. The logic of the Post Hoc Test is to compare each group (in these case typefaces) amongst themselves for each of the attributes examined. These results are not presented in this paper 
due to the large amounts of data. The results of Post Hoc Test follow the representation given through arithmetic mean.

Estimates of research variables for all typefaces. 20 attributes for eight typefaces were examined. Since the subjects valued their agreement with specific attributes on a Likert scale from 1 to 7 , their representation is given through arithmetic mean (Tab. 2) and graphically presented in Fig. 3.

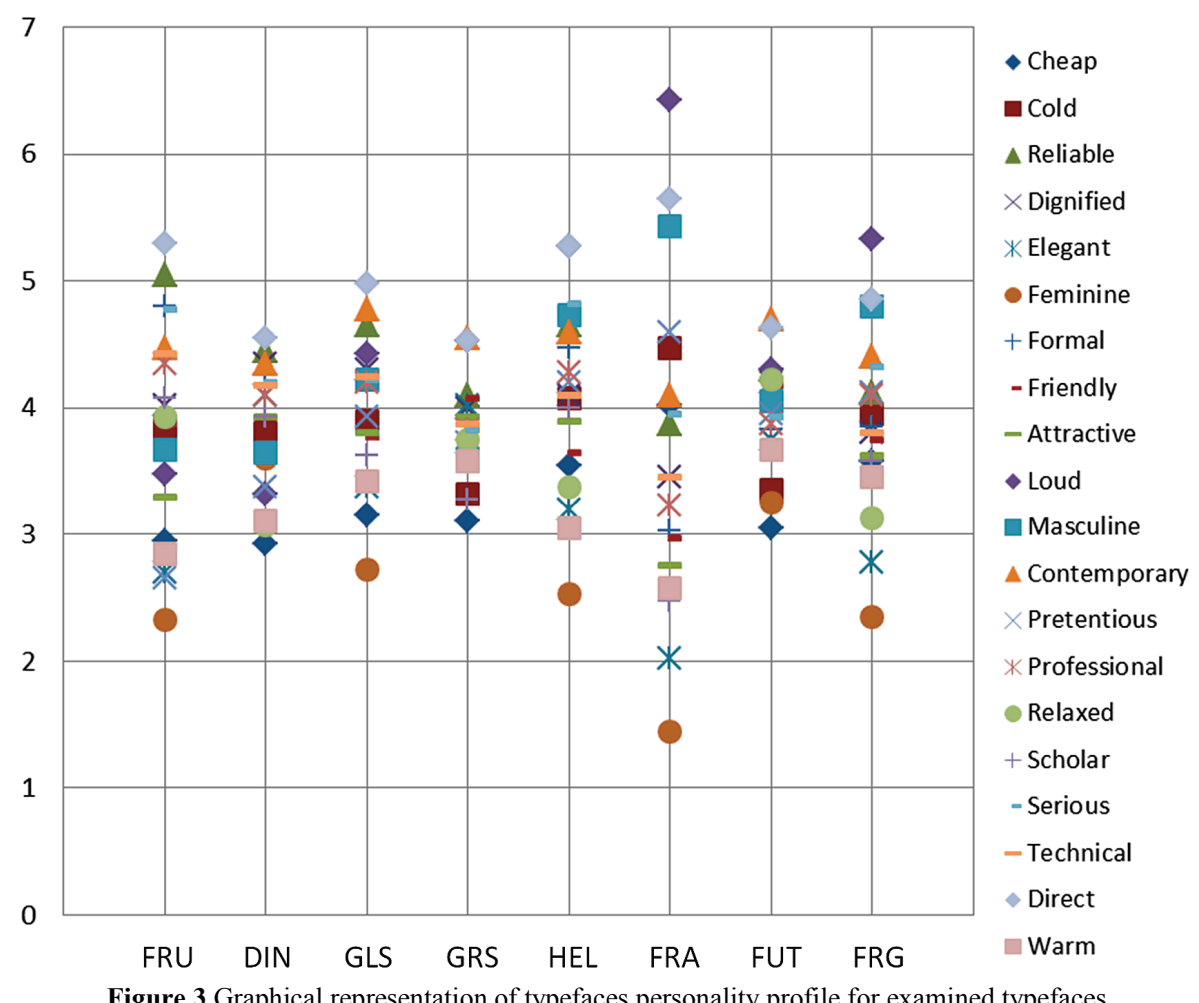

Figure 3 Graphical representation of typefaces personality profile for examined typefaces

\subsection{Binary code matrix analysis}

Through the qualitative stimuli analysis performed by the authors, it was observed that among eight formal attributes of typefaces (construction, shape, proportions, modelling, weight, terminations, key characters and decoration) defined by Catherine Dixon [19], weight i.e. character brightness was the area of the strongest difference between the typefaces. According to the observed, the digital image analysis for the typefaces examined was started by determination of their level of mean grey value, i.e. the average lightness intensity of these typefaces.

\subsubsection{Mean grey value}

Analysis of mutual relationship between the characters of the eight different typefaces was started by determining their mean grey value. Mean grey value analysis is often used in the process of digital image analysis, especially with the procedure of image segmentation, as well as the limiting of the filter influence in image processing [24, pp. 258-268]. Mean grey value is defined as the sum of intensity values of all the pixels present on the image divided with the total number of the pixels $[25$, p. 136]. The calculation of mean grey value can be presented as:

$P_{\text {avg }}=\frac{1}{M \times N} \sum_{i=1}^{M} \sum_{j=1}^{N} I_{\mathrm{mat}}(i, j)[26]$ where $M$ and $N$ represent the number of rows and columns of the digitalized image, Imat $(i, j)$ are the values of mean grey value at the position $(i, j)$.

Calculations of the mean grey value were done in three different, mutually independent programs: Matlab, ImageJ and Photoshop. The values (tab. 3) that were obtained by all three programs perfectly match. Furthermore, image preparation provided identical parameters for all samples. The samples were in Grayscale system, with minimum and maximum values of pixels of every sample adjusted in a way so that each of the sample pixels have 256 levels of brightness. Also, every sample was of identical dimensions, i.e. had the same total number of pixels. There was no need for samples prepared in this fashion to be converted in black and white image during the process of recalculation, which is why the calculation algorithm was given this form:

$$
\begin{aligned}
& \text { img1G = imread('1G.tif'); } \\
& \text { mean(mean(img1G(:, :, 1))) // }
\end{aligned}
$$

or:

mean(mean(img1G))

thr = graythresh $(\mathrm{img} 1 \mathrm{G})$;

thr_img $=$ im2bw(img $1 \mathrm{G}, \mathrm{thr})$;

triangle_count $=\operatorname{sum}(\operatorname{sum}($ thr_img $<$ thr $))$

Measuring samples were taken from the test instrument used in the experiment. For measurement 
purposes representation of each typeface was taken independently in: i) alphanumeric sequence (with the resolution of $1401 \times 235$ pixels), ii) complex paragraphs of typical text for each typeface (with the resolution of $1348 \times 556$ pixels).

Table 3 Results of brightness and mean grey value measurements.

\begin{tabular}{|c|c|c|c|c|}
\hline & $\begin{array}{c}\text { Alphanumeric } \\
\mathrm{M}\end{array}$ & $\begin{array}{c}\text { Alphanumeric } \\
\mathrm{K} \%\end{array}$ & $\begin{array}{c}\text { Paragraph } \\
\mathrm{M}\end{array}$ & $\begin{array}{c}\text { Paragraph } \\
\mathrm{K} \%\end{array}$ \\
\hline FRA & 212,245 & 16,968 & 196,462 & 22,982 \\
\hline FGR & 230,657 & 9,586 & 220,611 & 13,501 \\
\hline HEL & 232,818 & 8,705 & 223,125 & 12,607 \\
\hline DIN & 238,401 & 6,555 & 231,148 & 9,418 \\
\hline FUT & 233,834 & 8,277 & 225,933 & 11,411 \\
\hline GRS & 236,242 & 7,338 & 226,923 & 11,021 \\
\hline GLS & 235,417 & 7,764 & 228,867 & 10,246 \\
\hline FRU & 233,094 & 8,669 & 223,277 & 12,416 \\
\hline
\end{tabular}

\subsubsection{Structural similarity analysis SSIM}

Further examination is based on the analysis of structural similarity between the bitmap images of the examined typefaces. SSIM presents the similarity index based on three characteristics: brightness, contrast and structure. It needs to be mentioned that these three characteristics are relatively independent, whereas SSIM index is created with the objective of increased correspondence with human visual system [27].

SSIM compares pixels of one image with the pixels of another image. In order to define the referential image, the median value containing all samples was determined (Fig. 4). The index shows the similarities between the defined median value of all samples and the chosen sample. Median value of all samples was determined by overlapping every letter character with the matching letter character of all the other samples. All eight samples were placed in a layer where every pixel is matched with the pixel on identical $(x, y)$ position in the other samples. This results in a graphic representation of median value of intensity of every pixel. Thus gained image (Fig. 4) was compared, by means of SSIM matrix, with every sample separately and the index of similarity between the referential median sample and typeface sample was noted. Results obtained in this way show how much a certain sample is different from the referential median sample (Tab. 4).

\begin{tabular}{|l|l|l|}
\hline MD & $\begin{array}{l}\text { ABCDEFGHIJKLMnOporsturWXYz } \\
\text { abcdefghijkImnopqrsturwxyz } \\
1234567890\end{array}$ & a b C \\
\hline
\end{tabular}

Figure 4 Median of analysed typefaces and result details.

Table 4 Results of SSIM. Index value of 1 represents that two images match $100 \%$. As the index value falls closer to 0 , the difference between two compared images is bigger.

\begin{tabular}{|l|l|l|l|l|l|l|l|} 
FRA & FGR & HEL & DIN & FUT & GRS & GLS & FRU \\
\hline
\end{tabular}

\begin{tabular}{|l|l|l|l|l|l|l|l|l|}
\hline SSIM & 0,951 & 0,968 & 0,977 & 0,974 & 0,971 & 0,969 & 0,970 & 0,978 \\
\hline
\end{tabular}

\subsection{Relationships between typeface personality attribute variables and measured values of brightness}

Pearson's correlation coefficient was used for determining the connection between the examined variables.
Tab. 5 shows the results of examining the relationship between the examined personality attributes of typefaces and the results of digital code matrix analysis.

Table 5 Relationship between the subjects' estimates and measurement

\begin{tabular}{|c|c|c|c|c|c|c|}
\hline & & 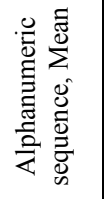 & 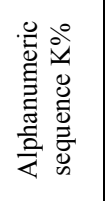 & 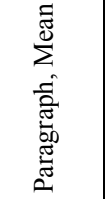 & 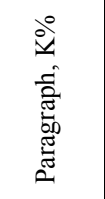 & 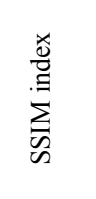 \\
\hline Cheap & $\mathrm{r}$ & $-.208 * *$ & $.207 * *$ & $-.208 * *$ & $.209 * *$ & -.100 \\
\hline Cold & $\mathrm{r}$ & $-.159 * *$ & $.160 * *$ & $-.157 * *$ & $.157 * *$ & -.008 \\
\hline Reliable & $\mathrm{r}$ & $.135 *$ & $-.134 *$ & $.136 *$ & $-.136^{*}$ & $.179 * *$ \\
\hline Dignified & $\mathrm{r}$ & $.168 * *$ & $-.168 * *$ & $.173 * *$ & $-.173 * *$ & .087 \\
\hline Elegant & $\mathrm{r}$ & $.344 * *$ & $-.345 * *$ & $.344 * *$ & $-.343 * *$ & .100 \\
\hline Feminine & $\mathrm{r}$ & $.399 * *$ & $-.400 * *$ & $.395 * *$ & $-.395 * *$ & $.117 *$ \\
\hline Formal & $\mathrm{r}$ & $.224 * *$ & $-.223 * *$ & $.222 * *$ & $-.222 * *$ & $.272 * *$ \\
\hline Friendly & $\mathrm{r}$ & $.195 * *$ & $-.196 * *$ & $.193 * *$ & $-.194 * *$ & .050 \\
\hline Attractive & $\mathrm{r}$ & $.231 * *$ & $-.232 * *$ & $.234 * *$ & $-.233 * *$ & .056 \\
\hline Loud & $\mathrm{r}$ & $-.485 * *$ & $.482 * *$ & $-.484 * *$ & $.485 * *$ & $-.301 * *$ \\
\hline Masculine & $\mathrm{r}$ & $-.342 * *$ & $.341 * *$ & $-.335 * *$ & $.336 * *$ & $-.185 * *$ \\
\hline Contemporary & $\mathrm{r}$ & .095 & -.096 & .100 & -.100 & .033 \\
\hline Pretentious & $\mathrm{r}$ & $-.192 * *$ & $.190 * *$ & $-.183 * *$ & $.185 * *$ & $-.194 * *$ \\
\hline Professional & $\mathrm{r}$ & $.180 * *$ & $-.179 * *$ & $.179 * *$ & $-.179 * *$ & $.188 * *$ \\
\hline Relaxed & $\mathrm{r}$ & $.183 * *$ & $-.185 * *$ & $.182 * *$ & $-.183 * *$ & .028 \\
\hline Scholar & $\mathrm{r}$ & $.263 * *$ & $-.262 * *$ & $.261 * *$ & $-.260 * *$ & $.231 * *$ \\
\hline Serious & $\mathrm{r}$ & .041 & -.040 & .037 & -.036 & $.155 * *$ \\
\hline Technical & $\mathrm{r}$ & $.128 *$ & $-.126^{*}$ & $.126^{*}$ & $-.127 *$ & $.175^{* *}$ \\
\hline Direct & $\mathrm{r}$ & $-.211 * *$ & $.212^{* *}$ & $-.211 * *$ & $.211 * *$ & -.025 \\
\hline Warm & $\mathrm{r}$ & $.148 * *$ & $-.150 * *$ & $.152 * *$ & $-.153 * *$ & -.014 \\
\hline \multicolumn{7}{|c|}{ **. Correlation is significant at the 0,01 level (2-tailed). } \\
\hline
\end{tabular}

Results of brightness measuring on the sample alphanumeric sequence, for the examined typefaces, are in a statistically significant negative correlation $(p \leq 0,01)$ with these attribute parameters: cheap, cold, loud, masculine, pretentious, and direct. This parameter is in positive correlation with: reliable, dignified, elegant, feminine, formal, friendly, attractive, professional, relaxed, scholar, technical and warm. When the alphanumeric sequence is presented in percentages, correlations appear that are the opposite of the previous ones. In other words, where the correlation was positive, it is now negative, and vice versa. Even though the correlations are significant on the level of 0,01 of statistical significance, correlation coefficients are low, which shows modest to moderate connections.

Examined relationship of brightness measurement results with typeface personality attribute parameters on the samples paragraph brightness and $\mathrm{K} \%$, shown in the Tab. 5, are consistent with the previous.

\subsection{Relationships between typeface personality attribute variables and measured values of similarity structure index}

Results of SSIM index measurements on the sample alphanumeric sequence, for the examined typefaces, are in a statistically significant positive correlation $(p \leq 0,01)$ with these attribute parameters: reliable, feminine, formal, academic, and serious; at the same time, they are in a statistically significant negative correlation with these attribute parameters: masculine, pretentious and loud 
(Tab. 5). Correlations are statistically significant at the level 0,01 ; however, correlation coefficients show modest connections.

\section{Comparative analysis of measurement results and experimental results}

Results of digital image analysis of brightness effect confirm that which was determined by qualitative analysis of the stimuli. Obtained values are presented in table 3 . The darkest typeface is Franklin Gothic/FRA, followed by Founders Grotesk/FGR. Subjects evaluated these typefaces with significantly higher marks for these attributes: loud, masculine, cold and cheap, on the basis of which it can be concluded that the typeface brightness attribute has a very influential effect on personality evaluation for the given attributes. Opposite of this effect, the brightest typeface is DIN, followed by typefaces Grid Sans/GRS, Gill Sans/GLS and Futura/FUT. In the same order subjects evaluated these typefaces as the most elegant and feminine.

Results of digital image analysis for the total attribute of form structures explain the marks for the attributes reliable, formal, pretentious, serious, academic; respectively: friendly and warm. Typefaces Frutiger/FRU and Helvetica/HEL are very similar to universal structure, which makes it easy to notice that subjects experience the universal typeface structure as something reliable, formal, serious, etc. Typefaces Futura/FUT and Grid Sans/GRS deviate from the universal in their skeletal structure, but at the same time they are brighter according to formal attribute, similarly to typefaces that are mentioned above (Frutiger/FRU and Helvetica/HEL). Due to such a combination of formal attributes, subjects experience these typefaces as friendly and warm.

Analysis of relationships between the variables suggests that the evaluation of typefaces according to specific personality attributes is connected with formal attributes. Results confirm that evaluation of certain personality attributes is influenced, in large measure, by one or another measured formal attribute. Modest correlations could be interpreted in several ways. In the first place, as a combined effect of two formal attributes. In other words, typefaces Franklin Gothic/FRA and Founders Grotesk/FGR deviate from universal structure because of their dark character. Secondly, according to Catherine Dickson [19], there are eight formal attributes in total, which is why the influence of each one of them can be considered confounding in this case.

\section{Discussion}

The results of statistical analysis confirmed that the even categorically selected typefaces, by purpose and style, could be experienced significantly differently among the subjects. When evaluating personality attributes for given typefaces, the subjects were influenced by formal attributes. By analysing representation of the variables based on the median mark values it was observed that the effect of brightness, respectively mean grey value, has a distinct influence on the way typeface is perceived. Franklin Gothic/FRA is the darkest typeface. It can be noticed that this typeface is the most variable based on the evaluated attributes, respectively, the results of the Post Hoc test show that this typeface makes the most frequently statistically significant differences by attributes. For each attribute, with the exception of the attribute serious, this typeface scored a distinctly highest or lowest average. Opposite of this effect, attributes elegant and feminine are characteristic for typeface DIN, which is the brightest, with a relatively narrow width. Characteristics of formal attributes with typeface Franklin Gothic/FRA, next to their combined influence on brightness or median grey value, represent the elements that deviate from the universal structure, respectively typeface skeleton. Typefaces that were evaluated by the subjects differ in the skeleton each in their own way, however, by qualitative analysis of stimuli it can be perceived that some of the typefaces more specifically deviate from that which is defined as common skeleton. For example, beside the already mentioned typeface Franklin Gothic/FRA, that obviously deviates from the common skeleton in its structure due to the overstated mean grey value, we can also notice distinct differences from it concerning the typeface Futura/FUT (Fig. 2/5), especially on the level of alograph of letter ' $a$ '. With this typeface, letter ' $a$ ' has a single-storey form by which in company of a large number of similar characters on which there is a forced inscription of circle in a square basis of letters it additionally strengthens the impression of abandoning a common humanistic skeleton. Letters 'p', 'q', 'b', 'd' and ' $\mathrm{g}$ ' in typeface Grid Sans/GRS have a specifically shortened stems in the places of junction with the bowl (Fig. 2/6). By analysing representation of single attributes, it can be seen that typefaces Futura/FUT and Grid Sans/GRS have, by their specific structure that deviates from the universal one, influenced the subjects to ascribe to them attributes like warm, attractive, friendly, or to mark the typeface Grid Sans/GRS as the least direct. Opposite of this effect, typeface Frutiger/FRU, which belongs to the sub-class of humanistic grotesk forms, i.e. supports by its structure universality of humanistic skeleton, was marked among all other typefaces as the most formal, the most professional and the most academic. Typeface Helvetica/HEL was marked as the most serious, and also, next to typeface Frutiger/FRU, as very formal and academic. By analysing the enclosed graph (Fig. 3), it can be seen that marks according to attributes vary in a greater and more significant measure based on the greater similarity (FRU) or difference (FRA) with the universal structure.

Judging by what has been perceived and presented, formal attributes have a conjoined and interlarded effect. Combined formal attributes of relative height, stroke width and character width seem like they produce the brightness effect of the typeface, or respectively, the relationship between white and black areas of positive, which stands out as the most influential specific characteristic. Attributes that also work together with these attributes are terminals, letter openness and allograph skeleton, in which way they influence to form the impression of a certain degree of familiarity with the universal, or typical appearance, which is why the subjects have different impressions. 
According to Henderson et al. [10], examination of universal characteristics facilitates greater generalization of the findings, while examination of specific characteristics facilitates formation of hypothesis on additional design factors. Specific characteristics can be researched by careful selection or design of the stimuli. By method that was applied in this research, in a series of experiments in which single attributes would be controlled and keep track of universal variables, it can be assumed that it would be possible to single out formal attribute effects as specific design characteristics.

\section{Conclusion}

Based on the comparative result analysis it can be clearly seen that deviation from the universal structure, respectively typeface skeleton, is a move towards the emphasis of specific attributes. It is our conclusion that the universal structure of the typeface is a universal characteristic, and that different deviations from the universal, like deviation from brightness or skeleton emphasizes specific characteristics. Specific characteristic of typeface brightness is evaluated by subjects as extremely elegant and feminine, or loud, masculine, cold and pretentious. Typeface brightness stands out in this research as the most influential specific characteristic. Deviation of typeface skeleton from the universal structure is evaluated by subjects as friendly and warm. High similarity with the universal structure is experienced as formal, reliable, serious, etc.

This finding provides information useful to any user of typefaces, whether he manages deliverables of technical and business communication, or designs visual aids, and guides him to an easier problem-solving when it comes to choosing an appropriate typeface. The writings of theorists and findings of previous research were based on an educative framework of the past, when it was essential for each professional to adopt the system of typeface classifications, which, at this point in time, are not completely functional even for the designers they were written for (cf. [19]). Findings that indicate that formal attributes and conventions work together to build universal characteristics, according to which specific impressions are evoked, open the question of the functionality of existing classifications and the need of the redefinition of the old or the establishment of new, more purposeful classification systems of typefaces.

Identified universal characteristics and their own effects, i.e. the deviations from the characteristic, should be based on the epistemological knowledge about how various typefaces affect in different ways, which the users, when designing or setting the text, are not obliged to know. Instead of being familiar with the effects of certain typefaces, they will only have to know those universal, key and specific characteristics. It will facilitate manipulation of typography by reducing the knowledge only to the typeface effects without the awareness of certain effects of numerous typefaces in a wide range of existing ones that is the recommendations of pragmatic texts.

Further research of the effects of specific characteristics can be carried out by isolating a single formal attribute, like skeleton structure or $x$-height.
Following this, it would be necessary to design a few typefaces, varying only one variable. Recent studies where the aim was to investigate the variable that affects legibility indicate this need $[28,29]$.

\section{Acknowledgements}

This work was supported by the Serbian Ministry of Science and Technological Development, Grant No.: 35027 "The development of software model for improvement of knowledge and production in graphic arts industry".

\section{References}

[1] Brumberger, E. The rhetoric of typography: The persona of typeface and text. // Technical communication. 50, 2(2003), pp. 206-223.

[2] Fox, D.; Shaikh, A. D.; Chaparro, B. S. The effect of typeface appropriateness on the perception of documents. // Proceedings of the Human Factors \& Ergonomics Society 51st Annual Conference / Baltimore, 2007, pp. 464-468.

[3] Mackiewicz, J.; Moeller, R. Why people perceive typefaces to have different personalities. // Ipcc 2004, Proceedings of the International Professional Communication Conference, Minneapolis, 2004, pp. 304-313.

[4] Kastl, A. J.; Child, I. L. Emotional meaning of four typographical variables. // Journal of Applied Psychology. 52, 6(1968), pp. 440-446. DOI: 10.1037/h0026506

[5] Kostelnick, C. The Rhetoric of Text Design in Professional Communication. // Technical Writing Teacher. 17, 3(1990), pp. 189-202.

[6] Bartram, D. The perception of semantic quality in type: Differences between designers and non-designers. // Information design journal. 3, 1(1982), pp. 38-50. DOl: 10.1075/idj.3.1.04bar

[7] Childers, T. L.; Jass, J. All Dressed Up With Something to Say: Effects of Typeface Semantic Associations on Brand Perceptions and Consumer Memory. // Journal of Consumer Psychology. 12, 2(2002), pp. 93-106. DOI: 10.1207/S15327663JCP1202_03

[8] Poffenberger, A. T.; Franken, R. B. A study of the appropriateness of typefaces. // Journal of Applied Psychology. 7, 4(1923), pp. 312-329. DOI: 10.1037/h0071591

[9] Davis, R. C.; Smith, H. J. Determinants of feeling tone in typefaces. // Journal of Applied Psychology. 17, 6(1933), pp. 742-764. DOI: 10.1037/h0074491

[10] Henderson, P. W.; Giese, J. L.; Cote, J. A. Impression management using typeface design. // Journal of Marketing. 68, 4(2004), pp. 60-72. DOI: 10.1509/jmkg.68.4.60.42736

[11] Doyle, J. R.; Bottomley, P. A. The Massage in the Medium: Transfer of Connotative Meaning from Typeface to Names and Products. // Applied Cognitive Psychology, 23, 3(2009) pp. 396-409. DOI: 10.1002/acp.1468

[12] Doyle, J. R.; Bottomley, P. A. Dressed for the Occasion: Font-Product Congruity in the Perception of Logotype. // Journal of Consumer Psychology. 16, 2(2006), pp. 112-123. DOI: 10.1207/s15327663jcp1602_2

[13] Morrison, G. R. Communicability of the Emotional Connotation of Type. // Educational Communication and Technology. 34, 4(1986), pp. 235-244.

[14] Rowe, C. L. The Connotative Dimensions of Selected Display Typefaces. // Information Design Journal. 3, 1(1982), pp. 30-37. DOI: 10.1075/idj.3.1.03row

[15] Tannenbaum, P. H.; Jacobson, H. K.; Norris, E. L. An experimental investigation of typeface connotations. // Journalism \& Mass Communication Quarterly. 41, 1(1964), pp. 65-73. DOI: 10.1177/107769906404100108 
[16] Brumberger, E. The rhetoric of typography: the awareness and impact of typeface appropriateness. // Technical Communication. 50, 2(2003), pp. 224-231.

[17] Tomiša, M.; Vusić, D.; Milković, M. The impact of the historical development of typography on modern classification of typefaces. // Tehnicki vjesnik 20, 5(2013), pp. 905-911.

[18] British Standards Institution, Typeface Nomenclature and Classification. Vol. 2961. London, 1967.

[19] Dixon, C. Describing typeforms: a designer's response. // InfoDesign: Brazilian Journal of Information Design, 5, 2(2008), pp. 21-35.

[20] On the choice of typefaces. // The Crystal Goblet: Sixteen Essays on Typography / Beatrice Warde. Cleveland and New York: The World Publishing Company, 1956, pp. 137149.

[21] Kinross, R. The Rhetoric of Neutrality. // Design Issues. 2, 2(1985) pp. 18-50. DOI: 10.2307/1511415

[22] Tschichold, J. The New Typography: A Handbook for Modern Designer. The First English Translation of the Revolutionary 1928 Document. London: University of California Press, 1995.

[23] Frutiger, A. Signs and Symbols: Their Design and Meaning, New York: Watson-Guptill Publications, 1998.

[24] Jähne, B. Digital Image Processing, Springer, 2005.

[25] Ferreira, T.; Rasband, W. The ImageJ user guide: ImageJ/Fiji 1.46. Revised edition, ImageJ, 2012.

[26] Anand, A. Tracing of interference fringes using average gray value and simultaneous row and column scan. // Optics \& Laser Technology. 35, 2(2003), pp. 73-79. DOI: 10.1016/S0030-3992(02)00143-3

[27] Wang, Z. Bovik, A. C. Sheikh, H. R. Simoncelli, E. P. Image Quality Assessment: From Error Visibility to Structural Similarity. // IEEE Transactions on Image Processing. 4, 13(2004), pp. 600-612. DOl: 10.1109/TIP.2003.819861

[28] Beier, S. Larson, K. Design Improvements for Frequently Misrecognized Letters. // Information Design Journal. 18, 2(2010), pp. 118-137. DOI: 10.1075/idj.18.2.03bei

[29] Beier, S. Larson, K. How does typeface familiarity affect reading performance and reader preference? // Information Design Journal. 20, 1(2013), pp. 16-31. DOl: 10.1075/idj.20.1.02bei

\section{Authors' addresses}

\section{Uroš Nedeljković, Associate Professor}

University of Novi Sad, Faculty of Technical Sciences, Trg Dositeja Obradovića 6, 21000 Novi Sad, Serbia

E-mail: urosned@uns.ac.rs

\section{Dragoljub Novaković, PhD Professor}

University of Novi Sad, Faculty of Technical Sciences, Trg Dositeja Obradovića 6, 21000 Novi Sad, Serbia

E-mail: novakd@uns.ac.rs

\section{Ivan Pinćjer, Teaching Assistant}

University of Novi Sad, Faculty of Technical Sciences, Trg Dositeja Obradovića 6, 21000 Novi Sad, Serbia

E-mail:pintier@uns.ac.rs 